\title{
The Life Cycle of Converging Industries: The Evolution of the Tablet Sector and Its Impact on Competitive Dynamics
}

\author{
Paolo Calvosa ${ }^{1}$ \\ ${ }^{1}$ Department of Economics, Management, Institutions (DEMI), University of Naples Federico II, Naples, Italy \\ Correspondence: Paolo Calvosa, Department of Economics, Management, Institutions (DEMI), University of \\ Naples Federico II, Campus Monte S. Angelo, Via Cinthia 26, 80126, Naples, Italy. E-mail: calvosa@unina.it
}

Received: August 22, 2021

Accepted: September 30, 2021

Online Published: October 20, 2021

doi:10.5539/ijbm.v16n11p76

URL: https://doi.org/10.5539/ijbm.v16n11p76

\begin{abstract}
Background of the study. In recent years a series of academic research projects in the economic managerial field have investigated the relationship between innovation and industrial evolution, providing new interpretive keys to improve the understanding of one of the most important events in the industries' transformation in the current economy, that of digital convergence.

Purpose of the paper and methodology. This research work provides an original contribution to the question of how market convergence affects industry evolution. The paper analyzes the convergence process that has influenced the evolution of the tablet sector and the dynamics of entry, exit, innovation and competition over the industry life cycle. From a methodological point of view, a historical-longitudinal study was carried out, which was aimed at examining - supported by a qualitative/quantitative analysis - the sequence of events that, over 30 years, influenced the development of the tablet industry.

Findings and implications. From the analysis some interesting findings emerged. Firstly, it was found that the life cycle curve of the converging tablet industry defined on the basis of sales data followed the 'S-shaped pattern' empirically detected by product and industry life cycle studies. Secondly, we have verified that the evolution of firm population and the level of product innovation in the tablet industry are consistent with two temporal patterns that characterize the evolutionary model, identified by evolutionary economics and technology management studies. It has also been found that the sectoral convergence process has affected the dynamics of competition in the tablet industry. It emerged, in fact, that the leading companies in introductory stages of the development of the tablet market - which came from the personal computer industry - quickly lost their market position in favor to newcomer firms that came from different converging sectors. The analysis has also made it possible to highlight that tablet market leaders tend to compete with each other in multiple sectors within the scope of a broader convergent mobile digital device market. Therefore, a 'hybrid competition' seems to have been affirmed between technological devices - smartphones, notebooks, tablets, smartwatches, e-readers different in shape, but united by satisfying, in different ways, a need for simplified access on the move to a series of advanced digital functions and services.
\end{abstract}

Keywords: industry life cycle, digital convergence, tablet, personal computer, innovation, competition

\section{Introduction}

Starting from the 1990s of the last century, and with the definitive manifestation of the effects of the 'digital revolution', a process of convergence has taken place by virtue of which the boundaries of the Information and Communication Technologies (ICT) sectors have become increasingly changeable and difficult to define (Yoffie, 1997).

This has caused a profound reconfiguration of structural and competitive dynamics in various markets, which then determins forms of 'hybrid competition' (Ancarani \& Costabile, 2009) which takes place between companies from different fields of activity. Among all the ICT sectors in which the convergence process has brought about extremely rapid and significant changes in recent years, it is worth noting the tablet PC industry. Born in the 1990s as small mobile devices that enabled, while on the move, some of the typical functions of desktops and laptop PCs, tablets have become over time advanced multifunctional devices, characterized by a usability more similar to that which characterizes smartphones. The current tablets, in fact, are multitouch 
devices that combine, in a single apparatus, some basic functions of personal computers with that of e-readers, digital music players, digital cameras, video terminals, and of portable video game consoles. In addition, they allow to access to a range of advanced services via the Internet, by the use of a variety of mobile software applications.

The transformation of the technological characteristics and the use of tablets has been accelerated decisively by a process of digital convergence, the effects of which became evident in the second decade of the new millennium. This has led to a radical change in product customer targeting and on the competitive structures of the various sectors affected by this convergence process.

The profound evolution of the technological and user characteristics of tablets supported by the industry convergence has been accompanied by a very rapid evolution of the sales of these devices. Sales in the tablet industry around the world, which until the end of the first decade of the new millennium remained very limited and absolutely residual compared to those of the broader PC industry (in which they fell as a product category), have increased exponentially from 2010, since the launch of the iPad tablet by Apple Inc.. If we analyze the market data provided by International Digital Corporation, it emerges that it has in fact passed, in only 5 years, from a total of about 5 million units sold in 2009, to a total of about 230 million units sold in 2014. However, this period was followed by a trend decrease in sales that saw it reach a total of about 164 million units in 2020, giving a glimpse of a sort of industry sales rise and fall process.

The study of the development dynamics of this sector appears to be of particular interest. As noted (Kim, Lee, Kim, Lee, \& Suh, 2015), in fact, despite the empirical evidence that the overall industry convergence has been increasing over time, the understanding of this phenomenon is still limited. This is also because with time technology convergence is evolving into a more complex and heterogeneous form (Jeong, Kim, \& Choi, 2015). The analysis of the changes that have connotated the evolution of the tablet sector, therefore, allow us to provide a contribution - from a economic-managerial perspective - regarding the specific modes under which the processes of convergence cause significant discontinuities in production and technological architectures of the sectors affected by these processes, and can cause a redefinition of the structural and competitive characteristics in converging sectors.

To examine these complex issues, the indications of scholars are useful in showing how the characteristics of industries vary over time, following in most cases a life cycle which is characterized by a series of empirical regularities concerning how entry, exit, market structure, and technological innovation vary from the birth of industries through to their maturity (Klepper, 1996). These contributions were developed mainly within the study perspectives of evolutionary economics (Nelson \& Winter, 1982; Gort \& Klepper, 1982; Klepper, 1996, 1997) and technology management studies (Abernathy \& Utterback, 1978; Utterback \& Suarez, 1993; Anderson \& Tushman, 1990; Audretsch, 1995; 1997).

Starting from the consideration that "convergence takes place at the intersection of change between technologies, industries, products, and markets" (Lind, 2005, p. 14), some scholars (Stieglitz, 2002; Hacklin, 2008; Hacklin, Marxt, \& Fahrni, 2009; Uzunca, 2018; Calvosa, 2020) have entered the study of convergence processes within an integrated theoretical framework that explicitly uses the assumptions of industry life cycle theories to deepen analysis of the relationship between industrial convergence, innovation processes and selective mechanisms that operate in defining the evolution of industries involved in sectoral convergence processes.

These types of studies provide new interpretative keys to shed light on one of the main events of sectoral transformation on which the attention of researchers in the managerial field has been focused in recent years. In addition, this helps to fill in some gaps regarding the classic model of the industry life cycle, especially when industrial evolution is influenced by 'distruptive events' such as those caused by technological convergence (Giachetti \& Marchi, 2010).

In line with the approach followed by these studies, this research work provides an original contribution to the question of how market convergence affects industry evolution. The objective of the work - described in greater detail in the next paragraph - is to analyze the phases of the convergence process that have determined the evolution of the tablet industry and the dynamics of entry, exit, innovation and competition over the industry life cycle.

The aim is, in particular, to verify whether, in line with the indications of the evolutionary and technology management theories, the evolution of this converging industrial sector was characterized by some empirical regularities that usually connotate the evolution of firms and industries over time. 
The outline of this paper is the following. In the next section, a literature review concerning the processes of sectoral convergence and industry life cycle theories is carried out in full. Then, the aims of the study are specified. In Section 3 the research methodology is described. Section 4 analyzes the main phases of the convergence process underlying the development of the tablet industry and the results of an empirical analysis aimed at examining the processes of entry, exit, innovation and competition over the industry life cycle. Section 5 presents conclusions and future research directions.

\section{Literature review and aims of the study}

The theme of convergence between markets can be traced back to Rosenberg's (1976) studies on the birth and evolution of the US machine tool industry, which showed how different industries, which were not correlated from the point of view of their final products, were however closely related in the technologies underlying their processes of production.

Over time, a number of studies have shown that in many cases the technology convergence at the sectoral level is accompanied by a convergence between products created and offered on the market (Gambardella \& Torrisi, 1998). Therefore, independent sectors from the point of view of supply and demand quickly overlapped and transformed, giving rise to new converging sectors characterized in some cases by well-defined boundaries; in other cases with ever-changing boundaries that are difficult to define (Weaver, 2007).

In the field of economic-managerial literature, starting from the 1990s, a series of research contributions examined the phenomenon of sectoral convergence seen as the "confluence and merging of hitherto separated markets, removing entry barriers across the market and industry boundaries" (Lind, 2005, p. 2). Most of them have primarily gone deeply into the analysis of the driving factors that brought about this process and the examination of different types of convergence (Katz, 1996; Yoffie, 1997; Greenstein \& Khanna, 1997; Pennings \& Puranam, 2001; Geum, Kim, \& Lee, 2016; Sick, Preschitschek, Leker \& Bröring, 2019).

Other studies have examined, in a broad sense, the impact of the sectoral convergence process on technology and business strategies and on the competencies needed to face the changes imposed by this process (Chakravarthy, 1994; Kaluza, Blecker, \& Bischof, 1999; Lei, 2000; Bores, Saurina, \& Torres, 2003; Lee, Lee, \& Cho, 2009; Lee, Olson, \& Trimi, 2010; Bröring, 2010; Aaldering, Leker, \& Song, 2019).

Over time, studies on industry convergence have increasingly used the indications deriving from empirical research carried out in the field of evolutionary economics and technology management. These research studies have detected the main recursive phenomena in the evolution of the structural and innovative characteristics of industrial sectors (Gort \& Klepper, 1982; Anderson \& Tushman, 1990; Utterback \& Suarez, 1993; Jovanovic \& MacDonald, 1994; Klepper 1996, 1997; Klepper \& Simons, 1996; Audretsch, 1997; Agarwal, Sarkar, \& Echambadi, 2002; Dinlersoz \& MacDonald, 2009; Bos, Economidou, \& Sanders, 2013; Tavassoli, 2015; Brenner \& Dorner, 2017; Haiyan, Ahmed, \& Nanere, 2020; Cucculelli \& Peruzzi, 2020). The results of these researches, in deepening the analysis of the evolutionary patterns that characterize the industrial sectors during the product life cycle - in connection with in the seminal works of Abernathy (1978) and Abernathy and Utterback (1978) - allowed the identification of a wide range of temporal and cross-sectional regularities that concern industry evolution and to understanding that innovation dynamics influence in a decisive way the entry and exit of companies and, therefore, the structure of the sectors over time.

Some scholars have therefore used evolutionary economics and industry life cycle theories such as integrative interpretations of the phenomenon of sectoral convergence. This allowed us to deepen the study of the evolution of converging sectors, assuming that convergence impacts on the redefinition of sector borders, changing the type of knowledge and skills that feed the innovation processes of companies and, as a result, industry competitive dynamics.

Stieglitz (2002), in remark, contributes to the question of what kind of impact market convergence has on innovations, market structure, and company behavior. He proposes an analysis framework built on evolutionary economics and industry life cycle theories, which allows us to understand how the different types of market convergence can determine different effects on industry evolution. To illustrate the framework, it has been applied to explain the evolution of the handheld computer market during the last 20 years of the last millennium. As he observes (2002, pp. 35-36), from the empirical analysis "it was shown that different types of convergence shaped the evolution of handheld computers at various times. The observed patterns of market evolution broadly correspond to the theoretical patterns of market convergence".

Hacklin, Marxt, and Fahrni (2009) carry out a study to provide a solution to a research question to which the academic literature does not seem to have answered unequivocally. Such scholars ask themselves if, at sector 
level, the convergence is associated with disintegration, entry and growth, or whether it is related the phenomenon of opposite effects, such as consolidation and shakeouts. To do this, they analyze the co-evolutionary processes that have characterized some ICT sectors by leveraging the indications of the studies on innovation cycles and proposing, on the basis of the results of their analysis, a model for the study of the convergence understood as an innovation process that influences evolutionary, technological and structural trajectories, at sectoral level.

Uzunca (2018), in order to 'shed light' on the competition between incumbents and entrants firms when one verifies inter-sectoral convergence processes, proposes a theoretical framework based on a competence-based view of industry evolution which allows us to examine the effects of the technological and market convergence between submarkets. The framework is tested to study the impact of submarket convergence on the evolution of the global semiconductor manufacturing industry. The research allows us to interpret how the competence profiles of hitherto separate submarkets evolved over time when these submarkets converge, allowing firms to leverage their competences across submarkets. The study, in explaining the evolutionary phases of the sector, shows, in line with the research hypotheses, that a convergence in both technological and customer competences favors industry incumbents over entrants. Instead, a lack of convergence in either type of competence gives competence entrants more probabilities to potentially disrupt industry incumbents.

Calvosa (2020), through an empirical research, examines the digital convergence process that led to the development of the smartphone sector and the dynamics of entry, exit and innovation over the industry life cycle. He verified if several empirical regularities that characterize the evolution of firms and industries over time have distinguished also an industry born from a sectoral convergence process. From the analysis it emerged that the evolution of market sales and of product innovation in the smartphone industry, as well as firms entry and exit dynamics, are consistent with the evolutionary model identified by technology management and industry life cycle studies. It has also been found that the convergence process favored the entry and the survival of new entrants, compared to the incumbent firms, that came from the native converging sectors.

In accordance with the approach followed by these studies, and for this research work, evolutionary economics and technology management theories are used to examine the evolution of one of the sectors that in recent years has been most influenced by the digital convergence process, that of the tablet PC.

The general objective of the study is, as already highlighted, to analyze the phases of the convergence process that have determined the evolution of the tablet sector and the dynamics of entry, exit, innovation and competition over the industry life cycle.

The use of a longitudinal analysis approach, based on the study of the historical sequence of events that has supported the development of the tablet industry permits us to verify if some empirical regularities that normally characterize the evolution of firms and industries over time also characterized the evolution of this converging sector. In particular, three specific aspects relating to the evolution of the tablet pc industry were examined.

First, in accordance with the indications of the product life cycle scholars (Vernon, 1966; Rink \& Swan, 1979) which showed how the various phases of this cycle are defined and distinct in relation to the different levels of sales growth in the sector, the evolution of the life cycle curve is described on the basis of the worldwide sales for such devices. This allows us you to verify:

1. if the product life cycle curve for the tablet industry followed the 'S-shaped pattern' - mainly identified by empirical research conducted in various industries by scholars of the product life cycle - or if instead it has taken on a different trend, which can be linked to one of the types of alternative configurations identified in the literature.

A second aspect analyzed concerns the study of the entry and exit processes of companies in the tablet industry. As highlighted, empirical studies on the life cycle of the sector have made it possible to identify some temporal patterns about the industries evolution. In particular, in relation to the entry and exit processes it emerged that most of the technologically progressive sectors follow an evolution of the industrial demography that goes through successive stages. More specifically, it emerged that normally the number of companies grows in the early stages of the industry development, and then reaches a peak, after which it declines steadily (Klepper, 1996). We then proceed to verify, in line with this temporal pattern:

2) even if in a sector that developed on the basis of a sectoral convergence process, such as that of tablets, the number of companies increased in the early stages of industry development, reached a peak, and then began to decline over time. 
Finally, a third aspect analyzed relates to the study of innovation processes during the development of the life cycle of the tablet industry. Also on this aspect, the studies carried out in the field of evolutionary economics and the technology management perspective have revealed an empirical regularity that characterizes the evolution over time of most sectors. In fact, these studies have shown that, expecially for industries with rich opportunities for both product and R\&D processes, product innovations are usually very frequent in the initial stages of development of a sector, and then later decline over time to the advantage of an increase in process innovations. It was then examined, in line with a specific temporal pattern found in the literature:

3 ) if in the convergent tablet industry the number of product innovations reached a peak during the growth phase of number of producers, and then declined over time.

\section{Methodology.}

From a methodological point of view, a qualitative/quantitative analysis was carried out which was aimed at studying in depth the life cycle of the tablet sector. A method of historical analysis consistent with the study of phenomena that can only be understood by examining the sequence time and the type of events underlying the structural and competitive transformations of a sector (Nelson \& Winter, 1982; Gort \& Klepper, 1992).

More specifically, in line with the specific aims of the work:

- to verify if the product life cycle curve for the tablet sector has followed the 'S-shape model', the life cycle curve of the tablet sector for the period 2005-2020 was constructed by elaborating market data provided by one of the leading specialized research institutes in the sector, International Digital Corporation (IDC);

- to analyse the levels of entry, exit and innovation over the industry life cycle and the changes in the competitive dynamics that have accompanied the evolution of the sector, an empirical research was carried out aimed at describing the evolution over time of the number and the type of companies operating in the tablet industry globally, as well as analyzing product innovations launched on the market by these companies. The data relating to the tablet manufacturers active in the period 2010-2020, provided by the database managed by 'GSM Arena'. GSM Arena is an independent website that continuously collects information on the worldwide production of digital devices (mobile phones/smartphones and tablets) and leads to accurate analysis of the technological characteristics of these devices. The trustworthiness of this database is indirectly confirmed by previous research of an economic-managerial nature (Cecere, Corrocher, \& Battaglia, 2015; Giachetti \& Dagnino, 2014; Giachetti \& Marchi, 2010) that used the data to analyze the dynamics of change in the mobile phone industry.

The companies included in the GSM Arena database operate internationally. They are therefore excluded those 'domestic operators' active only in one or a few national contexts. The resulting dataset contains 644 tablet models launched on the market during the period 2010-2020 by 44 market operators. To support the analysis, there were also used a series of supplementary data which was collected through the websites of companies operating in the tablet sector (especially in the form of annual reports and press releases), as well as the use of the information relating to the history and evolution of the tablet industry and others related sectors in academic publications, research reports and press releases of institutions specializing in the analysis of relevant converging industries.

\section{Results and Discussion}

\subsection{The Birth and Development of the Tablet Industry: The Effects of the Sectoral Convergence Process}

The concept of the tablet was born to present a digital device of small size that enables use on the move of some of the typical functions of the normal computer (Sena \& Sena, 2013). The first tablet prototypes were built, since the 90s of the last century, from a small number of companies producing PCs, including in particular the Japanese company Fujitzu. They exploited the progress in the field of microprocessors and in the production of batteries to create mobile devices, smaller and lighter than laptop PCs, but larger and heavier than Personal Digital Assistants (PDAs). Such devices operated primarily through the use of a digital pen (although some of them could still have a keyboard as an accessory), so pen touch and handwriting recognition were the primary data entry methods (McClard \& Somers, 2000).

In 2002, the market launch by Microsoft of convertible PC tablets that used a new operating system designed specifically for this type of device - Windows XP Tablet PC Edition - led several manufacturers of personal computers to introduce products in tablet form based on the use of the software Windows, which were placed along side traditional PC-type desktops and laptops. The placing on the market of these types of devices allowed users, as explained by Microsoft, to enjoy differential benefits, compared to notebooks and desktop PCs, in terms of mobility and flexibility of use. The creation of these devices, however, did not give rise, in the strict sense, to 
the development of a distinct sector of activity, as tablets still adopted the original concept of the interface of PCs and, therefore, the launch of these products appeared framed within a strategy of completing the range of models offered by companies producing personal computers. The first tablets launched on the market were also characterized by a rather high price and by a still limited memory and functionality (O'Neill, 2012), and as well as being non user friendly devices. In fact, until the first decade of the new millennium this type of apparatus was still conceived as an instrument capable of supporting the use of the functionalities of a computer in aid of professions that required high mobility in work (often in the form of a 'rugged tablet') and in the educational sector (Anderson, Schwager, \& Kerns, 2006; Nguyen, Barton, \& Nguyen, 2015). Sales of this type of device, therefore, remained for a long time very limited, representing an absolutely residual portion of the total sales of personal computers.

2010 is the year in which we witnessed a radical change, both in the configuration of the hardware features and software of the tablet. This happened with the introduction on the market by the Apple Inc. of the iPad tablet. Specifically, Apple used for the iPad, adapting them, the hardware design and their own mobile operating system iOS, which was already used since 2007 for their smartphone iPhone. In particular, the use of the mobile operating system designed for cell phones made it possible to greatly simplify the use of the various functions of a tablet PC, especially those related to Internet services (Scully, 2016). This software allowed, moreover, the 'transportation' from the world of the smartphone iPhone of a graphic interface based on the use of a selection of easy to use 'icons', together with a multitouch screen with a high graphic resolution, making it possible to interact with the tablet quickly and intuitively (a solution then imitated by most of the competitors and established itself as a standard).

The Apple device has therefore followed in the tablet market the same type of value innovation that had determined the sales success of the iPhone (Calvosa, 2015). The company, in fact, identified in the consumer market the main target to whom to supply a new form of mobile digital device which is easy to use, thus shifting the attention from the business market, to which it the tablet had been mainly addressed until then, to a mass market. Coherently with the target identified, access was made possible also for the iPad, through the App Store, to a host of multimedia applications with the aim of providing services to add value for the customer. This made it possible to make Apple's tablet a multifunction device that the users could personalize on the basis of their needs, as proven by the high sales statistics realized over time by such virtual store (Jia, Guo, \& Liu, 2020). In addition, the characteristically advanced hardware and iOS operating system made such a mobile device particularly high performance for listening to MP3 music format (also in relation to the competencies developed with the production of the iPod), for the display of video, as well as for word processing and graphics design (Scully, 2016). Finally, such device allowed connection to the Internet not only via Wi-Fi technology, as was the case for the majority of tablets hitherto produced, but also by means of a connection to the GSM network, allowing therefore the further advantage to provide connectivity anywhere, especially in a period in which Wi-Fi networks were not yet very widespread and affordable (Goldman \& Goldman, 2010; Khuhro et al., 2016).

The innovations introduced by Apple were immediately appreciated by the market. The company, as noted by the IDC, in 2010, the year the product was launched, sold about 15 of the 19 million tablets sold worldwide. The introduction of the iPad, therefore, contributed significantly to the growth of a market that, just a year earlier, had reached just 5 million units sold. The launch of the iPad, in particular, has accelerated the development of a digital convergence process between different sectors in the field of ICT (PC, mobile phone/smartphone, personal digital assistant, consumer electronics, digital publishing and telecommunication systems), which in the following years would have determined the affirmation of an industry significantly different from that of personal computers. Such a convergence process seem to be linked in a decisive manner to a series of technological innovations - exploited by Apple for realizing the iPad device - such as: the improvement of the microprocessor processing power (which allowed the passage from an Intel X86 architecture to a more highly performing and lighter ARM architecture); the enhancement of the band for data transmission, through the adoption of new digital standards for GSM, 3G, 4G and now 5G mobile communications; the enhancement and diffusion of Wi-Fi networks; the creation of dedicated 'lightweight' mobile operating systems. Just relying on these advances in ICT technologies it has been possible, in fact, to abandon the previous paradigm which was the basis of the concept of the tablet, anchored to an user interface similar to that of personal computers, in favor of a different conception of a mobile hybrid device, characterized by a usability more similar to that which characterizes smartphones.

\subsection{The Results of the Empirical Research: The Sales Curve of the Tablet Industry}


The description of the factors and of the main steps that have led to the development of the tablet sector allows us to better understand the results related to the first specific aims of the research, regarding the study of the evolution of the curve of life cycle of the tablet industry based on global sales data.

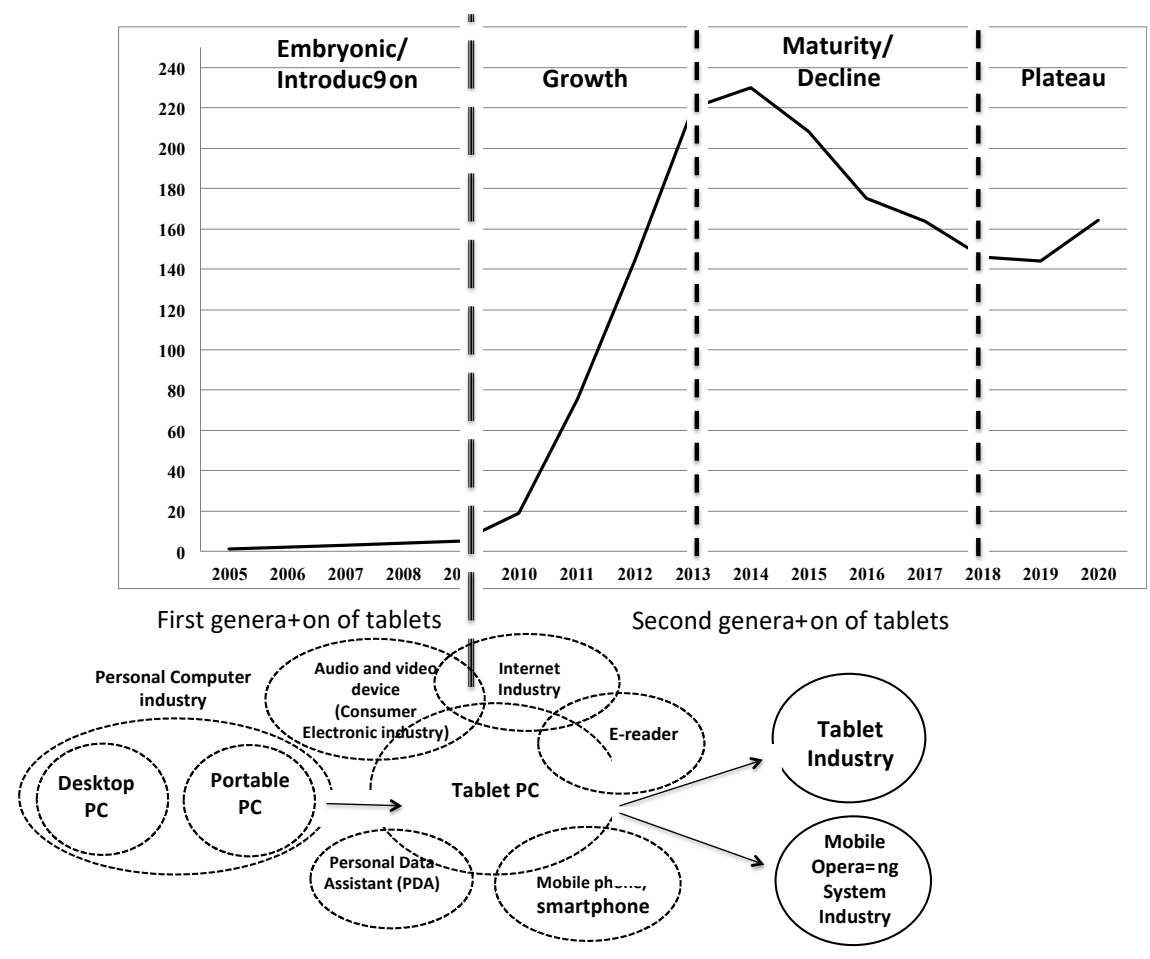

Figure. 1. The sales curves of the tablet industry and the convergence process (sales in the world of tablet, millions of units). Years 2005-2020.

Source: our processing of data from International Digital Corporation (IDC).

As graphically shown in Figure 1, the life cycle curve of the sector is characterized by different evolutionary phases, defined on the basis of the different levels of sales growth. The analysis of this trend allows for certain considerations:

1. Before 2010, tablet sales were very limited. You can then describe this phase as a period of embryonic/introductory development of the industry, during which the first generation of tablets which were not user friendly, had characteristics consistent with the aim of providing, primarily to business customers, a device of small size that would guarantee a use in motion of the most effective and typical functionality of a personal computer. In this first phase of development, therefore, the market sales of tablet fell into the context of a choice of completing the range of products offered by manufacturers of personal computers;

2. Since 2010 it was witnessed the quick development of the industry, on the basis of extremely high annual sales growth rates (two to three digits). This is the effect of the introduction on the market of the Apple iPad which, as described, has accelerated a process of digital convergence fueled by a series of technological innovations, reconfiguring the idea and the possibilities of using a tablet and, hence, its target market. This has given rise to a convergent industry significantly distinct from that of personal computers, in which companies from different ICT sectors have entered - as schematically illustrated in Figure 1 and further detailed in this text - such as those of smartphones/features phone, personal digital assistants, consumer electronics, digital publishing and telecommunications systems;

3. As of 2014, the sector appears to have entered a phase of maturity/decline. The sales growth rate, in fact, first declined sharply, and then became negative from 2015;

4. Since 2019, the rapid fall in sales that had characterized the previous four years seems to have stopped. In 2020, in particular, sales started to grow to 14 percent over the previous year, beginning to outline a phase of market 'plateau'. In fact, as observed (IDC, 2021a), the increase in sales seems in part caused by a growth in 
demand in the consumer and education segments due to working from home and learning online which are connected to the effects of the Covid pandemic. However, the industry is not expected to maintain this momentum in the long term, as it will still face stiff competition from other hybrid digital devices. It can not therefore say whether the phase of decline in sales has definitively stopped. Only analysis relating to the sales data in the coming years will provide sure guidance for future stages of development of the industry.

In a nutshell, it is therefore possible to highlight that the trend of the life cycle curve of the tablet sector, built on the basis of sales data up to 2020 , seems to have tended to follow the 'S-shaped model' identified by empirical research conducted on the subject, even if some aspects of the curve make its shape more specifically resemble one of the peculiar types of product life cycle identified by studies on the subject (Rink \& Swan, 1979), that of the 'growth-decline-plateau'.

\subsection{The Results of the Empirical Research: The Evolution of Firm Population over the Industry Life Cycle of the Tablet Sector}

A second aspect examined, coherently with the specific objectives of the research, was to verify whether - in line with one of the empirical regularities identified by the studies of the industry life cycle in technologically progressive sectors - during the different development phases of the tablet sector, the number of companies grew initially and then reached a peak, after which it declined steadily (Klepper, 1996). To do this, as specified within the description of the methodology of work, the data provided by the 'GSM Arena' database was processed to examine the number and type of active companies in the tablet sector at international level in the period 2010-2020.

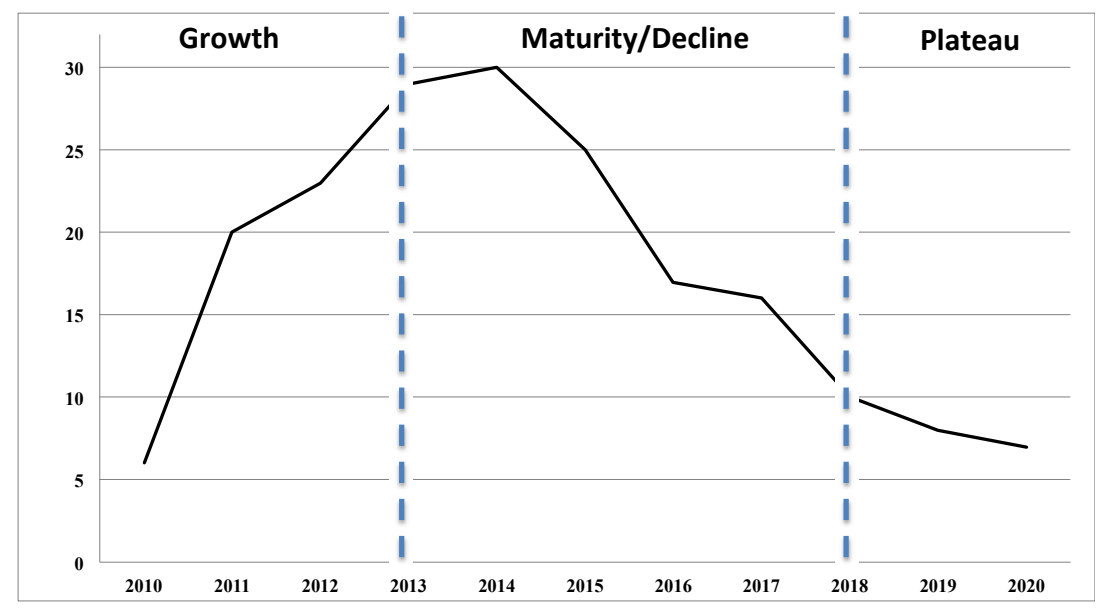

Figure 2. Firm population over the ILC of the tablet sector (number of companies). Years 2010-2020.

Source: our processing of GSMarena data (www.gsmarena.com).

The analysis showed that the companies operating in the tablet sector at an international level in that period totaled 44. More specifically, as graphically described in Figure 2, the total number of companies, based on different entry and exit levels, grew rapidly in the initial phase of sales growth, at the end of which it reached a peak. This was followed, with the entry of the sector into a maturity/decline in sales, to a marked decrease of numbers of tablet manufacturers. The trend over time of the firm population of this convergent sector, therefore, appears in line with one of the patterns concerning the nature of industry evolution, proposed by the literature on the industry life cycle.

\subsection{The Results of Empirical Research: Product Innovation over the Industry Life Cycle of the Tablet Sector}

Another aspect analyzed was that relating to the study of innovation processes during the life cycle of the tablet sector. In line with the specific aims of the work, it was verified whether - in accordance with one of the temporal pattern identified in the literature relating to the development of innovation processes during the industry life cycle - also in the convergent tablet sector, product innovations grew in the initial stages of development of the sector, reached a peak during the phase of growth, and then decreased over time. It should be noted, as an introduction, that product innovation in an industry can be measured in different ways. In this study product innovation was measured by the number of new versions of the product launched on the market by tablet companies operating at an international level. Therefore, the data provided by the GSM Arena database relating 
to the new versions tablet launched on the market over the period 2010-2020 was processed. From the examination of the data it emerged that a total of 44 companies active during the analyzed period offered 644 different versions of tablets on the market.

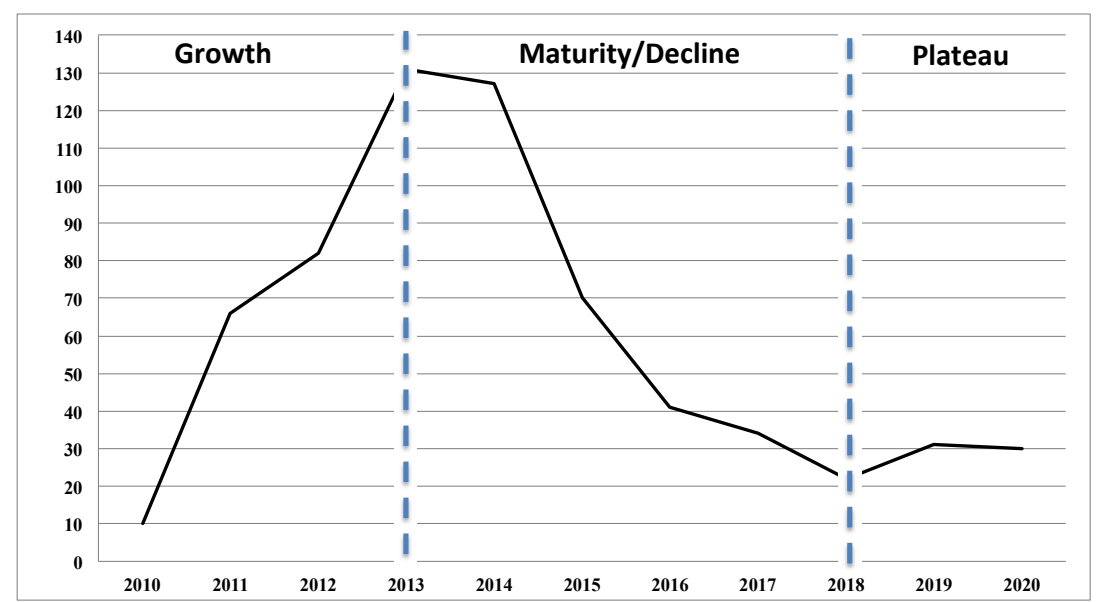

Figure 3. Product innovation over the ILC of the tablet sector: the number of new versions of tablet (Years 2010-2020)

Source: our processing of GSMarena data (www.gsmarena.com).

Figure 3 shows that the annual number of product innovations increased very rapidly in the sales growth phase of the tablet industry's life cycle and than reached a peak, to rapidly decrease in the maturing/decline sales phase (even if it seemed to have stabilized in the sales plateau phase).

The results, therefore, appear quite in line with one of the temporal patterns detected by the studies on the subject, when it is stated that, especially for industries with rich opportunities for both product and process R\&D, "the diversity of competing versions of the product and the number of major product innovations tend to reach a peak during the growth in the number of producers and then fall over time" (Klepper, 1996, p. 565).

\subsection{The Impact of Digital Convergence on Competitive Dynamics of Tablet Industry}

To conclude the discussion about the results of the empirical investigation just described, it is possible to deepen the analysis of these results - especially those relative to the sales data - to carry out some considerations relating to the changes in the competitive dynamics that have accompanied the evolution of the tablet converging sector.

In particular, it is possible to provide an industry case study contribution to a research question proposed in the literature (Anderson \& Tushman, 1990), relating to the effects of a technological discontinuity - such as that caused by the sectoral convergence process - on the competitive position of incumbent firms with respect to newcomer firms (in the case of the tablet sector, coming from converging sectors). To do this, comparison work was carried out between the market leaders in the period of embryonic/introductory development of the industry - before the sales growth started with the iPad's launch of Apple in 2010 - and those that dominate the market in 2020 .

In this regard, the data provided by IDC show that, up to 2010 almost 90 percent of the sales of the tablet market were controlled by five companies operating in the personal computer sector: Toshiba, HP, Fujitsu, Acer and Motion Computing. In 2020, however, as shown in Table 1, none of these incumbent operators hold relevant competitive positions. The 2020 sales data particularly indicates that the market leaders are newcomer companies that only entered the tablet sector after 2010 .

The information in Table 1 shows, in first place, the leadership position of Apple, with a market share in terms of units, accounting for 32.5 percent (even if it is more than halved compared to the data of 2010, year of launch of the iPad). Note also the very important position, with a market share of just under 20 percent of Samsung, that launched its first tablet in 2010 and was coming from the smartphone industry and, more generally, the consumer electronics market. It shows then the position of the Chinese company Huawei, with a market share of almost 10 percent. This company, coming from the networks telecommunications industry, in 2009 (three years before the 
production of the first tablet) had made its entry into the smartphone sector in which it is still operating in 2020 (Gartner, 2021). Since then, from the personal computer industry came another Chinese company, Lenovo, which has established itself as the fourth operator to market regularly, with an 8.6 percent share of sales. Even this company, a few years before the launch of the first tablet, which took place in 2011, had entered the smartphone sector with good sales results. In 2014 it then bought the mobility division of Motorola by Google for the value of about $\$ 3$ billion in an effort to penetrate the market for mobile digital devices (The Economist, 2014). The fifth market operator in terms of sales, Amazon.com, with a share very similar to that controlled by Lenovo, stands out for its origination from another converging sector, that of e-readers. The company, leader in the e-commerce industry, in 2007 had launched on the US market, through its e-commerce site, an electronic book reader, Kindle, that allowed you to connect to the Internet to download various types of content (books, newspapers and magazines), which used a software owner based on the open source operating system, Linux. The particular technology used for this e-reader, called 'E-ink', made it possible to imitate the appearance of the ink on a normal sheet of paper, allowing the reader to read for many hours, without straining the eyes as usually happens with the LCD displays used by computers and tablets (Juniper research, 2011). After the successful sales of this e-reader, the company in 2011 decided to also produce a tablet, Kindle Fire, based on the use of the Android operating system. This meant that in 2020 Amazon.com offered both e-readers and tablets, thus responding to different needs and targets.

Table 1. The competitive picture in the tablet sector in 2020: Worldwide shipments (millions of units), Market Share, Sector of origin of the company, Year of entry into the industry, Software operating system.

\begin{tabular}{cccccc}
\hline Vendor & $\begin{array}{c}2020 \\
\text { Unit } \\
\text { shipments }\end{array}$ & $\begin{array}{c}2020 \\
\text { Market } \\
\text { share }\end{array}$ & $\begin{array}{c}\text { Sectors } \\
\text { of origin }\end{array}$ & $\begin{array}{c}\text { Launch year } \\
\text { of tablet }\end{array}$ & $\begin{array}{c}\text { Software } \\
\text { operating } \\
\text { system }\end{array}$ \\
\hline Apple & 53.2 & 32.5 & $\begin{array}{c}\text { Personal Computer } \\
\text { (HD and SW) } \\
\text { Smartphone } \\
\text { Music digital device }\end{array}$ & 2010 & $\begin{array}{c}\text { iOS/iPadOS } \\
\text { (Proprietary) }\end{array}$ \\
Samsung & 31.3 & 19.1 & $\begin{array}{c}\text { Consumer electronics } \\
\text { Mobile/Smart phone } \\
\text { Personal Computer }\end{array}$ & 2010 & $\begin{array}{c}\text { Android } \\
\text { (Open source) }\end{array}$ \\
Huawei & 16.0 & 9.8 & $\begin{array}{c}\text { Telecommunication } \\
\text { Smartphone }\end{array}$ & 2012 & $\begin{array}{c}\text { Android } \\
\text { (Open source) } \\
\text { Lenovo }\end{array}$ \\
& 14.1 & 8.6 & Personal Computer & 2011 & $\begin{array}{c}\text { Android } \\
\text { (Open source) } \\
\text { Amazon.com }\end{array}$ \\
Others & 14.0 & 8.5 & E-commerce & 2011 & $\begin{array}{c}\text { Android } \\
\text { (Open source) }\end{array}$ \\
Total & 35.5 & 21.6 & E-readers & & \\
\hline
\end{tabular}

Source: our processing of data from IDC (2021a); gsmarena.com; pdabd.com; companies' business information (websites, reports, press releases).

One other important competitive change which has accompanied the evolution of the sector over time - that emerged from reading the Table 1 - relates to the type of operating system used in the tablet market. In fact, the growth of the tablet sector, such as the one that characterized the field of smartphones, has contributed to the success of the mobile operating systems market. In this regard, it is useful to remember that the trend in tablet sales is closely linked to that of software, as each sale of tablets corresponds to the sale/provision of a mobile operating system. In addition this business sector, which is closely linked with that of tablets and smartphones, the technological discontinuity caused by the digital convergence process seems to have completely changed its structural and competitive assets.

Up to 2010, the almost exclusive manufacturer of tablet operating systems was Microsoft, which provided the Microsoft CE version of its software under a paid license to most tablet manufacturers. 
As shown in Table 1, in 2020 two different software platforms in the market had established themselves. The first platform is iOS, a proprietary, closed source operating system released by Apple. The iOS operating system can be exclusively used on the tablet created by the same company that produces it, just as for the iPhone. In fact, since the launch of the first-generation iPad in 2010, Apple has used the same software designed for the iPhone, given that the iPad was architecturally akin to a big iPhone. Over time the iPad lineup has expanded into a wholly separate product category. Apple therefore in 2019 rebranded iOS for iPad as iPadOS, starting with iOS 13, to highlight and target the features that differentiate the iPad from other devices. It is interesting to note that this choice of adapting the software platform to the type of mobile device has also been adopted in other converging sectors in which Apple has since entered. It refers to the sector of smart watches, for which it created the 'watchOS' for Apple Watch, and to Internet devices connected to the TV, for which it created the 'tvOS' for Apple TV (Techrepublic, 2021).

As shown in Table 1, the other main market operators apart from Apple adopted instead the Android software. This operating system was created by Google in 2008, thanks to a strategic alliance involving 35 ICT companies - the Open Handset Alliance (OHA) - to be used on a new generation of smartphones. The development of the tablet sector prompted the company to offer the use of its operating system for this type of mobile device. For the tablet, and as already done for the smartphone, Google decided to make the Android operating system 'open source'. To be more precise, the company grants the software to tablet manufacturers license-free, but 'selectively open', in the sense that it is granted to companies that accept certain hardware and software conditions predefined by Google (Campbell-Kelly, Garcia-Swartz, Lam, \& Yang, 2015; Kenney \& Pon, 2011).

The situation thus outlined, makes it possible to point out that - as happened in the smartphone sector - a sort of duopoly has now established itself in the tablet operating system market. Google, in fact, provides the Android system to almost all manufacturers of tablets other than Apple. These manufacturers have thus been able to outsource the management of the device's software component. Apple, instead, with the proprietary closed iOS/iPadOS system, contributed to the stable success of its iPad model in the tablet market.

It should also be noted that Google seems to have followed the road opposite to that taken by Apple for the design of its Android system for tablet. In fact, the company initially launched a version of the software Android Honeycomb - specifically designed for devices with larger screens, in particular tablets. It quickly decided to go back on its steps, suggesting a later version of the software - Android Ice Cream Sandwich - with which it develops the changes introduced by the 'Android Honeycomb' version, designed exclusively for tablets, in an effort to create a unified platform for both tablets and smartphones, simplifying and unifying the overall user experience of Android regardless of the type of mobile device used.

The changes in the competitive dynamics just discussed, highlight in summary that, with the profound technological and market evolution of the tablet sector (and that of mobile software operating systems), the incumbent computer companies that were leaders in the introductory phase of ILC have rapidly lost their position in favor of newcomers firms, coming from different converging sectors.

However, if the horizon of analysis is broadened beyond the tablet sector, towards connected converging sectors, it is possible to carry out some further interesting considerations of a competitive nature.

Table 2. The market leaders in the tablet industry in 2020: industrial sectors and multiple competition.

\begin{tabular}{lccccc}
\hline \multicolumn{5}{c}{ Sectors } \\
\hline Vendor & Tablet & Smartphone & Smartwatch & $\begin{array}{c}\text { Personal } \\
\text { computer } \\
\text { (desktop e } \\
\text { laptop) }\end{array}$ & E-reader \\
\hline Apple & $\mathrm{x}$ & $\mathrm{x}$ & $\mathrm{x}$ & $\mathrm{x}$ & $\mathrm{x}$ \\
Samsung & $\mathrm{x}$ & $\mathrm{x}$ & $\mathrm{x}$ & $\mathrm{x}$ & \\
Huawei & $\mathrm{x}$ & $\mathrm{x}$ & $\mathrm{x}$ & $\mathrm{x}$ & \\
Lenovo & $\mathrm{x}$ & $\mathrm{x}$ & $\mathrm{x}$ & & $\mathrm{x}$ \\
Amazon.com & $\mathrm{x}$ & $(-)$ & & & \\
\hline
\end{tabular}

Source: our elaboration

Legend: (x) current sector of activity; (-) sector from which it has exited 
Table 2 shows the top five players in the tablet market in 2020 sorted in terms of sales (these companies overall control about two thirds of total worldwide sales in terms of units and even more in terms of revenues). For each of these business operators, it is shown the sectors in which they are multiple competitors, i.e. in competition in at least more than one sector.

Specifically, it should be noted that the top three market operators in the tablet sector are the same that occupy the top three positions in terms of sales in the smartphone and smartwatch sector, albeit with a change in relative positions. In the smartphone sector, in fact, in 2020 Samsung was market leader with a share in terms of units sold of around 19 per cent, closely followed by Apple with a market share of around 15 percent and Huawei with 13.5 percent (Gartner, 2021). In the smartwatch sector, on the other hand, it is Apple who holds the leadership in terms of units sold in 2020, with a market share of over 30 percent, followed by Huawei with a market share of around 11 percent and Samsung with a share of about 9 percent (Counterpoint Research, 2021). The integrated reading of the sales data of the tablet, smartphone and smartwatch sectors puts into light the extreme significance of the competitive interdependencies between these converging sectors.

In the personal computer sector, on the other hand, Lenovo holds the leadership position, with a market share in terms of units with 24 percent. Among other leading players in the tablet industry, only the position of Apple, which has a market share of 7.6 per cent (IDC, 2021b), is significant.

Finally, the table shows that Amazon, the fifth largest market operator in terms of sales in the tablet, also operates in the e-reader sector, in which it is a global market leader. In this sector Samsung also operated in the past, end the production of this type of device to focus on tablet production. It should be noted that, as reported in Table 2, Amazon also briefly operated in the smartphone market, with the launch in 2014 of the Fire Phone model. They then decided to exit the market after just two years because of the poor sales results.

The observations just made show that the tablet industry leaders tend to compete in multiple sectors within the scope of a broader convergent 'metamarket' of mobile digital devices, born under the relevant innovations in the field of information and communication technologies.

\section{Conclusions and Future Research Directions}

The analysis allows us to carry out, in line with the aims of the research, some concluding remarks on the evolutionary dynamics that have characterized the development of the convergence tablet sector.

The analysis showed, first of all, that the trend of the life cycle curve of the tablet sector, defined on the basis of different levels of sales growth, followed specific evolutionary phases that were in line with the regulatory indications of the studies on the product life cycle. Indeed, an S-shaped curve emerged characterized by a clear succession of the phases of introduction, growth, maturity and decline, which was however followed by a slight recovery/stabilization of sales in the last two years examined. The trend, therefore, highlights a model for the development of sales in the tablet sector which falls more precisely within the scope of one of the peculiar types of product life cycle identified by studies on the theme (Rink \& Swan, 1979), that of the 'growth-decline-plateau' type. The data analysis also allows us to point out that the transition from one phase to another in the life cycle of the sector was very rapid. As it turns out, a particularly short duration of the phases, appears connected not only to the characteristic of high dynamism typical of ICT sectors, such as the tablet sector, but also to the phenomenon of convergence on the basis of which this sector has evolved.

A second aspect that emerged from the analysis is that the evolution of firm population and the level of product innovation along the life cycle stages of the convergent tablet industry, are consistent with two temporal patterns that characterize the typical evolutionary model of technologically progressive industries identified through empirical research done by scholars of evolutionary economics and technology management. In fact, it resulted that also in the convergent tablet industry: 1) the number of companies grew initially and then reached a peak, after which it declined steadily; 2) the number of product innovations increased very rapidly in the sales growth phase of the tablet industry and then reached a peak, to rapidly decrease.

The research has also made it possible to describe the main changes in the competitive dynamics that have accompanied the evolution of the sector over time.

In particular, it was examined how the technological discontinuity caused by the sectoral convergence process has affected the competitive position of incumbent firms with respect to newcomers. It specifically emerged that the leading companies in introductory stages of the development of the tablet market - which came from the personal computer industry - quickly lost their market position in favor to newcomer firms that came from different converging sectors.

The in-depth analysis has also made it possible to highlight that in 2020 the tablet industry market leaders tend to 
compete with each other in multiple sectors within the scope of a broader convergent mobile digital device market. Therefore, hybrid competition processes emerge between technological devices - smartphones, notebooks, tablets, smartwatches, e-readers - different in shape, but united by satisfying, in different ways, a need for simplified access on the move to a series of advanced digital functions and services, mainly linked to the exploitation of the potential of Internet-based technologies. This opens up to the need to elaborate, in the sectoral contexts influenced by the processes of digital convergence, new conceptual models of analysis that make it possible to better examine the determinants of these new forms of hybrid competition. While adapting, in fact, the typical models adopted for the competitive analysis to the specific characteristics of the sectors in convergence, such models do not seem capable of fully grasping the competitive interrelationships determined by sectoral convergence processes, as they have been developed according to the study of the characteristics of an individual sector. In other words, an analysis that allows you to specifically deepen the strategic interdependencies that tend to characterize the evolution of several converging sectors, could take on the role of an integrative tool useful in helping to understand some of the aspects of the competitive strategies adopted by companies that are multiple competitors in different converging sectors, and are difficult to interpret using only traditional competitive analysis models proposed in the management literature.

\section{References}

Aaldering, L. J., Leker, J., \& Son, C. H. (2019). Uncovering the dynamics of market convergence through M\&A. Technological Forecasting and Social Change, 138, 95-114. https://doi.org/10.1016/j.techfore.2018.08.012

Abernathy, W. J. (1978). The productivity dilemma. Baltimore: The Johns Hopkins University Press.

Abernathy, W. J., \& Utterback, J. M. (1978). Patterns of Industrial Innovation. Technology Review, 80(7), 40-47.

Agarwal, R., Sarkar, M. B., \& Echambadi R. (2002). The conditioning effect of time on firm survival: an industry life cycle approach. Academy of Management Journal, 45(5), 971-994. https://doi.org/10.2307/3069325

Ancarani, F., \& Costabile, M. (2009). Concorrenza ibrida. Convergenza, tecnologie, esperienze di consumo. Milano: Pearson.

Anderson, J. E., Schwager, P. H., \& Kerns, R. L. (2006). The drivers for acceptance of tablet PCs by faculty in a college of business. Journal of Information Systems Education, 17(4), 429-440. https://doi.org/10.1016/j.techfore.2018.08.012

Anderson, P., \& Tushman M. (1990). Technological Discontinuities and Dominant Designs: A Cyclical Model of Technological Change. Administrative Science Quarterly, 35(4), 604-633. https://doi.org/10.2307/2393511

Audretsch, D. B. (1995). Innovation and Industry Evolution. Cambridge MA: The MIT Press.

Audretsch, D. B. (1997). Technical regimes, industrial demography and the evolution of industrial structures. Industrial and Corporate Change, 6(1), 49-82. https://doi.org/10.1093/icc/6.1.49

Bores, C., Saurina, C., \& Torres, R. (2003). Technological convergence: a strategic perspective. Technovation, 23(1), 1-13. https://doi.org/10.1016/S0166-4972(01)00094-3

Bos, J. W., Economidou, C., \& Sanders M. W. J. L. (2013). Innovation over the industry life-cycle: Evidence from EU manufacturing. Journal of Economic Behavior \& Organization, 86(1), 78-91. https://doi.org/10.1016/j.jebo.2012.12.025

Brenner, T., \& Dorner, M. (2017). Is there a life cycle in all industries? First evidence from industry size dynamics in West Germany. Applied Economics Letters, 24(5), 289-297. https://doi.org/10.1080/13504851.2016.1184369

Bröring, S. (2010). Developing innovation strategies in times of market convergence. International Journal of Technology Management, 49(1/2), 272-294. https://doi.org/10.1504/IJTM.2010.029421

Calvosa, P. (2015). Cycles of Convergence and Dynamics of Growth in the Smartphone Industry. European Scientific Journal, 19(11), 1-28. Retrieved from https://eujournal.org/index.php/esj/article/view/5925/5710

Calvosa, P. (2020). Entry, Exit and Innovation over the Industry Life Cycle in Converging Sectors: An Analysis of the Smartphone Industry. International Journal of Business and Management, 15(12), 151-168. https://doi.org/10.5539/ijbm.v15n12p151.

Campbell-Kelly, M., Garcia-Swartz, D., Lam, R., \& Yang, R. (2015). Economic and business perspectives on smartphones as multi-sided platforms. Telecommunications Policy, 39(8), 717-734. https://doi.org/10.1016/j.telpol.2014.11.001 
Cecere, G., Corrocher, N., \& Battaglia, R. D. (2015). Innovation and competition in the smartphone industry: Is there a dominant design? Telecommunications Policy, 39(3-4), 162-175. https://doi.org/10.1016/j.telpol.2014.07.002

Chakravarthy, B. S. (1994). Flexible Commitments: Coping with Chaos. Working paper, INSEAD, Fontainebleau. Retrieved from https://flora.insead.edu/fichiersti_wp/inseadwp1994/94-17.pdf

Counterpoint Research. (2021). Global Smartwatch Shipments Market Share (2018Q1 - 2021Q1). Press Release, May $25 . \quad$ Retrieved from https://www.counterpointresearch.com/global-smartwatch-shipments-market-share/

Cucculelli, M., \& Peruzzi, V. (2020). Innovation over the industry life-cycle. Does ownership matter? Research Policy, 49(1). https://doi.org/10.1016/j.respol.2019.103878

Dinlersoz, E. M., \& MacDonald, G. (2009). The industry life-cycle of the size distribution of firms. Review of Economic Dynamics, 12(4), 648-667. https://doi.org/10.1016/j.red.2009.01.001

Gambardella, A., \& Torrisi, S. (1998). Does technological convergence imply convergence in markets? Evidence from the electronics industry. Research Policy, 27, 445-463. https://doi.org/10.1016/S0048-7333(98)00062-6

Gartner (2021). Gartner Says Worldwide Smartphone Sales Declined 5\% in Fourth Quarter of 2020. Press Release, February 22. Retrieved from https://www.gartner.com/en/newsroom

Geum, Y., Kim, M., \& Lee, S. (2016). How industrial convergence happens: a taxonomical approach based on empirical evidences. Technological Forecasting and Social Change, 107, 112-120. https://doi.org/10.1016/j.techfore.2016.03.020.

Giachetti, C., \& Dagnino, G. B. (2014). Detecting the relationship between competitive intensity and firm product line length: evidence from the worldwide mobile phone industry. Strategic Management Journal, 35(9), 1398-1409. https://doi.org/10.1002/smj.2154

Giachetti, C., \& Marchi, G. (2010). Evolution of firms' product strategy over the life cycle of technology-based industries: a case study of the global mobile phone industry, 1980-2009. Business History, 52(7), 1123-1150. https://doi.org/10.1080/00076791.2010.523464

Goldman, D. F., \& Goldman, L. (2010). iPad survey results: Everything you need to know about how people use the iPad. Business Insider, November 13. Retrieved from http://www.businessinsider.com/ipad-survey-results-2010-11?op=1

Gort, M., \& Klepper, S. (1982). Time Paths in the Diffusion of Product Innovations. Economic Journal, 92(367), 630-653. https://doi.org/10.2307/2232554

Greenstein, S., \& Khanna, T. (1997). What does industry convergence mean? In D. Yoffie (Ed.), Competing in the Age of Digital Convergence (pp. 201-226). Boston, MA: Harvard Business School Press.

Hacklin, F. (2008). Management of Convergence in Innovation. Heidelberg: Physica Verlag.

Hacklin, F., Marxt, C., \& Fahrni, F. (2009). Coevolutionary Cycles of Convergence: An Extrapolation from the ICT Industry. Technological Forecasting and Social Change, 76(6), 723-736. https://doi.org/10.1016/j.techfore.2009.03.003

Haiyan, D., Ahmed, K., \& Nanere, M. (2020). Life cycle, competitive strategy, continuous innovation and firm performance. International Journal of Innovation Management, 25. https://doi.org/10.1177/21582440211032169

IDC - International Digital Corporation. (2021a). Worldwide Tablet Shipments Return to Growth in 2020, Fueled by Unprecedented Demand, According to IDC. IDC Media Center. February 1. Retrieved from https://www.idc.com/getdoc.jsp?containerId=prUS47423721

IDC - International Digital Corporation. (2021b). PC Sales Remain on Fire as Fourth Quarter Shipments Grow 26.1\% Over the Previous Year, According to IDC. IDC Media Center. January 11. Retrieved from https://www.idc.com/getdoc.jsp?containerId=prUS47274421

Jeong, S., Kim, J., \& Choi, J. Y. (2015). Technology convergence: What developmental stage are we in? Scientometrics, 104, 841-871. https://doi.org/10.1007/s11192-015-1606-6.

Jia, H., Guo, C., \& Liu, X. (2020). Smartphone and Tablet Application (App) Life Cycle Characterization via Apple App Store Rank. Data and Information Management, 4(1), 
44-67. https://doi.org/10.2478/dim-2020-0002

Jovanovic, B., \& MacDonald, G. (1994). The Life Cycle of a Competitive Industry. Journal of Political Economy, 102(2), 322-347. https://doi.org/10.1086/261934

Juniper Research. (2011). Tablets: Viva la evolution. White papers. Extract from: Tablet \& eReader Evolution $\begin{array}{lllll}\text { Strategies \& } & \text { Opportunities } & \text { 2011-2016. } & \text { Retrieved }\end{array}$ https://www.juniperresearch.com/whitepapers/Tablets_Viva_La_Evolution

Kaluza, B., Blecker, T., \& Bischof, C. (1999). Implications of digital convergence on strategic management. In S. B. Dahiya (Ed.), The Current State of Economic Science (pp. 2223-2249). Rohtak: Spellbound Publications.

Katz, M. L. (1996). Remarks on the Economic Implications of Convergence. Industrial and Corporate Change, 3, 1079-1095. https://doi.org/10.1093/icc/5.4.1079

Kenney, M., \& Pon, B. (2011). Structuring the smartphone industry: is the mobile internet OS platform the key? Journal of Industry Competition and Trade, 11(3), 239-261. https://doi.org/10.1007/s10842-011-0105-6

Khuhro, R., Qureshi, Q., Humayon, A., Tahir, S. \& Khan, A. (2016). Factors affecting adoption behavior for Tablet device among computer users in Pakistan. Management Science Letters, 6(12), 723-734. https://doi.org/10.5267/j.msl.2016.11.002

Kim, N., Lee, H., Kim, W., Lee, H., \& Suh, J. H. (2015). Dynamic patterns of industry convergence: Evidence from a large amount of unstructured data. Research Policy, 44, 1734-1748. https://doi.org/10.1016/j.respol.2015.02.001

Klepper, S. (1996). Entry, Exit, Growth and Innovation Over the Product Life Cycle. American Economic Review, 86(3), 562-583. Retrieved from https://www.jstor.org/stable/2118212

Klepper, S. (1997). Industry Life Cycles. Industrial and Corporate Change, 6(1), 145-181. https://doi.org/10.1093/icc/6.1.145

Klepper, S., \& Simons, K. L. (1996). Innovation and industry shakeouts. Business \& Economic History, 25(1), 81-89. Retrieved from https://www.jstor.org/stable/23703104

Lee, M., Lee, J., \& Cho, Y. (2009). How a convergence product affects related markets: The case of the mobile phone. ETRI Journal, 31(2), 215-224. https://doi.org/10.4218/etrij.09.0108.0574

Lee, S. M., Olson, D. L., \& Trimi, S. (2010). The impact of convergence on organizational innovation. Organizational Dynamics, 39(3), 218-225. https://doi.org/10.1016/j.orgdyn.2010.03.004

Lei, D. T. (2000). Industry evolution and competence development: the imperatives of technological convergence. International Journal of Technology Management, 19(7/8), 699-738. https://doi.org/10.1504/IJTM.2000.002848

Lind, J. (2005). Ubiquitous Convergence: Market Redefinitions Generated by Technological Change and the Industry Life Cycle. Paper for the DRUID Academy Winter Conference. Aalborg, Denmark.

Mcclard, A., \& Somers, P. (2000). Unleashed: Web tablet integration into the home. Proceedings of the SIGCHI conference on Human factors in computing systems. CHI Letters, 1(2), 1-8. Retrieved from https://dl.acm.org/doi/abs/10.1145/332040.332042

Nelson, R., \& Winter, S. (1982). An Evolutionary Theory of Economic Change. Cambridge MA: Harvard University Press.

Nguyen, L., Barton, S. M., \& Nguyen, L. T. (2015). iPads in higher education-Hype and hope. British Journal of Educational Technology, 46(1), 190-203. https://doi.org/10.1111/bjet.12137

O'Neill, S. (2012). The Evolution of the Tablet PC. Network World, October 12. Retrieved from https://www.cio.com/article/2368135/the-evolution-of-the-tablet-pc.html

Pennings, J. M., \& Puranam, P. (2001). Market Convergence \& Firm Strategy: New Directions for Theory and Research. Paper presented at the ECIS conference. The future of innovation studies, Eindhoven, the Netherlands, September 20-23.

Rink, D.R., \& Swan, J.E. (1979). Product life cycle research: a literature review. Journal of Business Research, 7(3), 219-42. https://doi.org/10.1016/0148-2963(79)90030-4

Rosenberg, N. (1976). Perspectives on technology. Cambridge: Cambridge University Press.

Scully, M. (2016). The History of the iPad. Proceedings of the New York State Communication Association: Vol. 
2015, Article 3. Retrieved from https://docs.rwu.edu/nyscaproceedings/vol2015/iss 1/3

Sick, N., Preschitschek, N., Leker, J., \& Bröring, S., (2019). A new framework to assess industry convergence in high technology environments. Technovation, 84, 48-58. https://doi.org/10.1016/j.technovation.2018.08.001

Sena, J. A., \& Sena, M. P. (2013). The tablet evolution and diffusion. Proceedings of the Information Systems Educators Conference, 30, San Antonio, Texas, USA. Retrieved from http://proc.edsig.org/2013/pdf/2534.pdf

Stieglitz, N. (2002). Industry dynamics and types of market convergence: The evolution of the handheld computers market in the 1990s and beyond. Paper presented at the DRUID summer conference. Copenhagen/Elsinore. Retrieved

from http://citeseerx.ist.psu.edu/viewdoc/download?doi=10.1.1.112.2393\&rep=rep1\&type=pdf

Tavassoli, S. (2015). Innovation determinants over industry life cycle. Technological Forecasting and Social Change, 91, 18-32. https://doi.org/10.1016/j.techfore.2013.12.027

TechRepublic. (2021). Apple iPadOS: A cheat sheet. Software, April 26. Retrieved from https://www.techrepublic.com/article/apple-ipados-everything-you-need-to-know/

The Economist. (2014). Google and Lenovo. Motonovo. Business and management, January 30. https://www.economist.com/schumpeter/2014/01/30/motonovo

Utterback, J. M., \& Suarez, F. (1993). Innovation, Competition, and Industry Structure. Research Policy, 22(1), 1-21. https://doi.org/10.1016/0048-7333(93)90030-L

Uzunca, B. (2018). A competence-based view of industry evolution: The impact of submarket convergence on Incumbent-entrant dynamics. Academy of Management Journal, 61(2), 738-768. https://doi.org/10.5465/amj.2015.1080

Vernon, R. (1966). International Investment and International Trade in the Product Life Cycle. Quarterly Journal of Economics, 80, 190-207. https://doi.org/10.2307/1880689

Weaver, B. (2007). Research proposal: industry convergence: driving forces, factors and consequences. Nordic Academy of Management Conference, 1-20. Retrieved from https://portal.research.lu.se/portal/files/6305586/1578598.pdf

Yoffie, D. B. (1997). Introduction: CHESS and competing in the age of digital convergence. In D. Yoffie (Ed.), Competing in the Age of Digital Convergence (pp. 1-35). Boston, MA: Harvard Business School Press.

\section{Copyrights}

Copyright for this article is retained by the author(s), with first publication rights granted to the journal.

This is an open-access article distributed under the terms and conditions of the Creative Commons Attribution license (http://creativecommons.org/licenses/by/4.0/). 